Onomástica Desde América Latina, n.3, v.2, janeiro - junho, 2021, p. 154 - 176 ISSN 2675-2719

https://doi.org/10.48075/odal.v0i0.25692

\title{
Nomeação de escolas como homenagem à histórica local do município paranaense de Marechal Cândido Rondon
}

\section{School names as homage to the local History of the Paraná county of Marechal Cândido Rondon}

\author{
Daniel Seidel Ruppenthal* \\ Universidade Estadual do Oeste do Paraná \\ https://orcid.org/0000-0002-9019-9521 \\ avengerplay1@gmail.com
}

\section{Resumo}

O presente artigo se centra na investigação dos nomes próprios atribuídos a escolas da cidade Marechal Cândido Rondon, no Paraná, tomando, como objeto de estudo, especificamente, escolas localizadas mais ao centro da cidade. A análise procurou recuperar quem são os sujeitos homenageados em cada nome das escolas, e, quando possível, por quais razões o nome foi escolhido. A metodologia empregada nesta pesquisa envolve a busca de fundamentação teórica e documental para o levantamento de dados históricos relacionados às escolas analisadas e análise dos dados com o aporte de outros estudos toponímicos com objetivo semelhante. A pesquisa revelou que um terço dos nomes de escola analisados correspondem a pioneiros no município; quatro nomes são de escritores e quatro de pessoas de notoriedade no cenário nacional; houve também dois casos de escolas que homenageiam os locais onde se encontram. Os resultados da pesquisa mostram que, a partir dos vestígios presentes nas denominações, o estudo toponímico dos nomes de escolas permite contemplar e resgatar uma parte do passado rondonense que está ligado a essas escolas.

Palavras-chave: Topônimo; Nomes de escola; História.

\begin{abstract}
The present article focuses on the investigation of proper names assigned to schools in Marechal Cândido Rondon city, in the state of Paraná, taking, as study object, specifically, schools near downtown. The analysis looked for recover who are the subjects honored in each name of the schools, and, when possible, for which reasons the name was chosen. The methodology employed on this research involves the demand of theoretical and documented foundation for the setting-up of historical data related to the analyzed schools and with the support on other similar goal toponymic studies. The research revealed that one third of the school names analyzed correspond to pioneers in the city; four are names of writers and four names of notorious people on the nation scene; there were also two cases of schools which honor the place where they are located. The results of the research show that, starting from the present vestiges on the denominations, the toponymic study of school names allow us to contemplate and rescue a part of the past of the city that is connected to these schools.
\end{abstract}

\footnotetext{
* Trabalho oriundo de Iniciação Científica voluntária orientada pela Professora Doutora Márcia Sipavicius Seide ao longo do ano letivo de 2020.
} 
Onomástica Desde América Latina, n.3, v.2, janeiro - junho, 2021, p. 154 - 176 ISSN 2675-2719

Keywords: Toponym; School names; History.

\section{Introdução}

A língua possibilita a interação entre os membros de uma sociedade e a expressão de sua cultura, pois a cultura e a língua estão intimamente relacionadas. O léxico detém marcas culturais, visto que reflete a visão de mundo da comunidade de fala, principalmente na área nominativa, dado que o homem expõe sua identidade sociocultural nos nomes designados, incluindo nos topônimos. Segundo Andrade (2017), "ao se estudar o léxico de uma língua, podese também apreender a realidade do grupo que a utiliza: cultura, história, modo de vida e visão de mundo" (ANDRADE, 2017: 586).

A língua enquanto produto social concentra significados experienciados na cultura de uma comunidade, uma vez que há, no léxico, conceitos antigos e atuais de uma sociedade, abarcando, dessa forma, todo o universo cultural passado e presente. Em outras palavras, o léxico é um patrimônio social, visto que a forma de contemplar o mundo varia de acordo com cada sociedade, evidenciando essa singularidade no léxico de sua língua.

O léxico completo de uma língua pode se considerar, na verdade, como o complexo inventário de todas as ideias, interesses e ocupações que açambarcam a atenção da comunidade; e, por isso, se houvesse à nossa disposição um tesouro assim cabal da língua de uma dada tribo, poderíamos daí interferir, em grande parte, o caráter do ambiente físico e as características culturais do povo considerado (SAPIR, 1961: 45 citado por BASTIANI, 2016: 22).

Por conta disso, pode-se traçar um perfil psicossocial e cultural de uma sociedade com base no estudo de topônimos uma vez que eles são designados a partir da relevância social do lugar, selecionando, assim, um nome pertinente ao grupo. Isso porque a linguagem proporciona a comunicação, a organização, a expressão e, por fim, a produção de significados, por meio da capacidade do homem de nomear a realidade. Ao nomear, o homem distingue a realidade e 
atribui sentidos únicos às coisas. Além disso, o conjunto lexical de um idioma revela diversos aspectos da comunidade que o utiliza:

O léxico, saber partilhado que existe na consciência dos falantes de uma língua, constitui-se no acervo do saber vocabular de um grupo sociolinguístico-cultural. $\mathrm{Na}$ medida em que o léxico configura-se como a primeira via de acesso a um texto, representa a janela através da qual uma comunidade pode ver o mundo, uma vez que esse nível da língua é o que mais deixa transparecer os valores, as crenças, os hábitos e costumes de uma comunidade, como também, as inovações tecnológicas, transformações socioeconômicas e políticas ocorridas numa sociedade (OLIVEIRA; ISQUERDO, 1998: 7 citado por BASTIANI, 2016: 24).

O topônimo, sendo uma das palavras-chave neste artigo, remete, assim como outros nomes, ao signo linguístico. Segundo Saussure (1916), um signo linguístico é composto pela união de um significado, como um conceito ou ideia em conjunto com uma imagem acústica (som) (SAUSSURE, 1916: 79-80). Com um triângulo representativo, Ogden e Richards (1923) explicam que um signo linguístico é composto por um significante (som/nome) que se refere a um símbolo, o qual é nada mais que um conceito que, por sua vez, representa algo ou alguém o qual o falante se refere (OGDEN; RICHARDS, 1923: 32 citado por BASTIANI, 2016: 28).

Quando nós ouvimos o que é dito, ambos os símbolos nos levam a executar um ato de referência e a tomar uma atitude na qual, segundo as circunstancias, serão mais ou menos similares ao ato e a atitude de quem fala (OGDEN; RICHARDS, 1923: 11, tradução nossa).

Para Ullmann, "há, portanto, uma relação recíproca e reversível entre o nome e a referência: se alguém ouvir a palavra pensará na coisa, dirá a palavra” (ULLMANN, 1964: 119 citado por BASTIANI, 2016: 29). Considerando estes posicionamentos, Blikstein (1995) defende que o referente, ou seja, a coisa, não pode ficar de fora da concepção linguística porque ela é a origem do significado (BLIKSTEIN, 1995: 39 citado por TAVARES, 2009: 98). Contudo, segundo Guiraud (1986), a convenção leva à desmotivação, e, portanto, à arbitrariedade, pois a according to circumstances, be more or less similar to the act and the attitude of the speaker (OGDEN; RICHARDS, 1923: 11). 
motivação é minorizada pela convenção e tende a ser alterada ou apagada. A convenção, por sua vez, tende a ressignificar a palavra quando está desmotivada (GUIRAUD, 1986: 27-28 citado por BASTIANI, 2016: 30). No âmbito dos signos linguísticos, Dick (1990) explica que os topônimos explicitam, no geral, a motivação do nome, sendo mais deduzíveis ao se relacionar o nome e o local.

[...] ainda que, na língua, o signo participe genericamente, de uma natureza convencional de significação, ao se aplicar o mesmo princípio à Toponímia notar-se-á uma diversidade de aspecto: o elemento linguístico comum, revestido de função onomástica ou identificadora de lugar, integra um processo relacionante de motivação onde, muitas vezes, se torna possível deduzir conexões hábeis entre o nome propriamente dito e a área por ele designada (DICK, 1990: 34 citado por BASTIANI, 2016: 30-31).

A nomeação dos lugares "sempre foi atividade exercida pelo homem, desde os primeiros tempos alcançados pela memória humana” (DICK, 1990: 5). Segundo Dick (1990), a motivação toponímica envolve a intencionalidade do denominador ao selecionar o nome por algum motivo e a origem semântica que confere significado ao nome e uma procedência (DICK, 1990: 39 citado por BASTIANI, 2016: 31). Para Dick, os aspectos físicos e os aspectos antropoculturais são os principais fatores de influência do denominador no momento da escolha do nome. A autora diz que o topônimo é como um espelho, pois ele reflete o contexto espaço-temporal da denominação e evidencia as influências e circunstâncias socioculturais constituintes da realidade do denominador (DICK, 1990: 50 citado por BASTIANI, 2016: 31). Ademais, Andrade tem o mesmo posicionamento de Dick ao dizer que "o signo toponímico é motivado, sobretudo, pelas características físicas do local ou pelas impressões, crenças e sentimentos do denominador" (ANDRADE, 2017: 587).

A partir da nomeação, uma coisa desconhecida, ou seja, sem sentido, passa a fazer parte da estrutura conceitual do indivíduo. A linguagem permite que o homem possa distinguir a 
Onomástica Desde América Latina, n.3, v.2, janeiro - junho, 2021, p. 154 - 176 ISSN 2675-2719

realidade nomeando os elementos que o cerca, classificando e significando-os. Para Seide (2013), “diferentemente dos nomes comuns, os antropônimos (nomes de pessoas) e os topônimos (nomes de lugar) são fruto de uma escolha por parte do designador, escolha feita de acordo com seus valores e sua visão de mundo, os quais são histórica e socialmente determinados" (SEIDE, 2013: 167).

É importante ressaltar que o nome porta uma memória associada a ele no próprio ato de nomeação ou por meio das relações que os indivíduos estabelecem com esse nome. Conforme defende Bastiani (2016), os documentos são memórias, e, portanto, patrimônios culturais. A pesquisa onomástica revela a história por trás dos nomes tendo em vista que, quando se associa um nome ao lugar, cria-se uma representação da relação do denominador com este local, num contexto específico. Para realizar o estudo dos nomes das escolas acessamos a memória preservada nos registros, documentos e outros indícios para desvendarmos a identidade da comunidade analisada, a fim de descobrir as motivações dos nomes por meio das memórias, definidas por Bastiani como "fatos passados significativos para a comunidade e, por isso, dignos de registro" (BASTIANI, 2016: 37).

Tendo isto em vista, a pesquisa apresentada neste artigo tem como objetivo resgatar parte da história das escolas do município através do estudo de como elas foram nomeadas.

O objetivo e o método dessa pesquisa têm o mesmo padrão do estudo de Faria (2018), no qual

A pesquisa teve como primeiro objetivo listar todos os antropotopônimos urbanos existentes na cidade de Ponte Nova, posteriormente, buscou-se encontrar a biografia das pessoas homenageadas com seus nomes nesses logradouros, procurando resgatar, assim, parte da história e da memória da cidade (FARIA, 2018: 1153).

O trabalho também se assemelha ao estudo de Brandão e Abbade (2016) cujo objetivo é 
apresentar um recorte da dissertação de mestrado defendida e aprovada no programa de Pós-Graduação em Estudo de Linguagens, na Universidade do Estado da Bahia, intitulada Guia de Ruas, (Bairros) e Mistérios: a toponímia como elemento identitário em Bahia de Todos os Santos (2015). A pesquisa supracitada analisou os topônimos referentes aos bairros e ruas da cidade de Salvador, encontrados em AMADO (2002 [1945]). Esse recorte diz respeito ao levantamento e estudo dos Antropotopônimos, ou seja, os nomes e/ou sobrenomes próprios de pessoas, utilizados para nomear os acidentes físicos e humanos que habitam a obra de Jorge Amado (2002 [1945]) utilizada como corpus da pesquisa (BRANDÃO; ABBADE, 2016: 313).

Ao contrário dos trabalhos de Faria (2018), Brandão e Abbade (2016), o presente trabalho traz uma pesquisa única na região estudada e observando apenas antropotopônimos que compõem nomes de escolas. O estudo toponímico realizado revela tendências que constituíram o passado enquanto expõem a identidade da sociedade rondonense.

Este artigo está organizado em três seções: além desta introdução, direcionada ao embasamento teórico a respeito dos nomes de lugares, a próxima seção traz a discussão dos conceitos toponímicos que nortearam a pesquisa e a explanação sobre os estudos toponímicos e seu multifacetado campo de pesquisa. A última seção do artigo descreve e discute os resultados obtidos.

\section{Toponomástica e interdisciplinaridade}

Compreendendo a complexidade dos estudos onomásticos, observamos a importância da interdisciplinaridade, tendo em vista as relações existentes entre os estudos linguísticos, geográficos, históricos e antropológicos. De fato, o estudo dos topônimos é uma divisão da onomástica cujas

questões poderiam, sem dúvida alguma, e com igual êxito, se inscrever nos quadros da História, da Geografia, ou das Ciências Sociais, por exemplo, e por elas serem solucionadas. (...) Isso porque é lícito considerar-se a Toponímia, antes de tudo, como um imenso complexo línguo-cultural, em que os dados das demais ciências se interseccionam necessariamente e, não, exclusivamente (DICK, 1990: 15-16). 
Onomástica Desde América Latina, n.3, v.2, janeiro - junho, 2021, p. 154 - 176 ISSN 2675-2719

Conforme é apresentado no trabalho de Bastiani, Andrade e Pereira (2018), a investigação onomástica realizada

se parte da interdisciplinaridade, tendo como contingente o pensamento complexo, para gestar a extensão conceitual de lugar em Toponímia, uma vez que a promoção do diálogo entre diferentes áreas do saber se constitui em uma tentativa de alcançar um conhecimento mais globalizante e menos fragmentado da realidade (BASTIANI; ANDRADE; PEREIRA, 2018: 113).

As autoras Prudente e Abbade (2019) apontam o uso da interdisciplinaridade em sua pesquisa toponímica, em que

o estudo desenvolvido, complementado por saberes de outras áreas do conhecimento científico, especialmente da História e da Geografia, permitiu identificar três principais estratos linguísticos na formação da toponímia baiana (PRUDENTE; ABBADE, 2019: 224).

Segundo Bastiani, Andrade e Pereira (2018)

Nos estudos toponímicos, o lugar deve ser entendido como algo além de uma simples localidade ou um espaço determinado, tendo em vista que, ao escolher um determinado nome para um lugar, o denominador passa a manter com ele uma relação de identidade (BASTIANI; ANDRADE; PEREIRA, 2018: 115).

Moreira e Hespanhol (2007) explicam que, para o geógrafo Yi-Fu Tuan (1983), o espaço se transforma em lugar ao ser experienciado, o que lhe confere valor e significação (MOREIRA e HESPANHOL, 2007: 04 citado por BASTIANI, 2016: 55). Para a Geografia Humanista, o lugar é um espaço significativo para o indivíduo, pois existe uma relação de identidade entre o indivíduo e o lugar (BASTIANI, 2016: 55-56). Como explica Bastiani, "tendo em vista que ao ato de nomear impregnam-se marcas sociais, históricas e culturais dos nomeadores, sendo que seus valores e sua cosmovisão se refletem no nome escolhido para batizar um espaço" (BASTIANI, 2016: 56). 
Onomástica Desde América Latina, n.3, v.2, janeiro - junho, 2021, p. 154 - 176 ISSN 2675-2719 https://doi.org/10.48075/odal.v0i0.25692

Bastiani esclarece que a relação lugar-nome-indivíduo é sustentada pela identidade e pertencimento. A identidade se dá por meio da semelhança encontrada pelo indivíduo entre a história do lugar e de sua própria história individual, pois o nome de um lugar carrega memórias históricas, culturais e sociais que se unem à memória individual. O pertencimento decorre da relação identitária pela qual o indivíduo passa a ter sentimentos de afetividade e de vínculo com o lugar (BASTIANI, 2016: 56). Do ponto de vista da Geografia Crítica, conforme explica a pesquisadora, "o lugar pode ser entendido como uma construção social", "pela fusão entre homem e espaço, por meio da qual um metamorfoseia o outro recíproca e constantemente" (BASTIANI, 2016: 58). No caso do espaço escola, ela se torna um lugar para o indivíduo após ele ter relações com outros indivíduos ali presentes, criando um vínculo entre aquele indivíduo e o espaço. Além disso, a escola é transformada pelo aluno enquanto este é também transformado pela escola, pois é compreendida como um espaço social (BASTIANI, 2016: 59-60).

Os topônimos exercem poder sobre um local, constituindo-os também como território, evidenciando a influência sociopolítica de um indivíduo ou grupo em um determinado lugar em certo momento histórico, assim a denominação de um lugar traz em estado latente a memória do denominador que se apropriou do lugar ao nomeá-lo. A escola como lugar é também vista como um território, sujeito à nomeação sob a influência ideológica do denominador, conferindo-lhe ou não valores que se relacionam com o nome. Contudo, o lugar é uma construção social, o que implica na possível alteração destes valores pelos indivíduos que constituem esse espaço vivido.

(...) levando em consideração que a escola é uma instância que transforma o indivíduo ao lhe possibilitar à aquisição dos conhecimentos, dos valores, das normas, e da consciência coletiva necessária à vivência harmônica em sociedade, o indivíduo também opera objetivamente na transformação e desenvolvimento dessa instituição enquanto espaço social. (BASTIANI, 2016: 62) 
Onomástica Desde América Latina, n.3, v.2, janeiro - junho, 2021, p. 154 - 176 ISSN 2675-2719

Concluída a apresentação da base teórica e conceitual da pesquisa, descrevemos e analisamos, nas seções a seguir, os dados coletados na região central da cidade Marechal Cândido Rondon.

\section{Descrição dos dados coletados}

Os nomes de lugar efetivamente investigados foram os relacionados a nomes próprios de pessoas, a saber, os antropotopônimos, axiotopônimos e hierotopônimos, visto que, essa última categoria toponímica engloba também alguns nomes próprios de pessoas. Quando um nome próprio de pessoa se torna um nome próprio de lugar há uma mudança intercategorial (LÓPEZ FRANCO, 2020) resultado de uma escolha que pode revelar os valores e a história de uma comunidade (REYES CONTRERAS, 2020). Segundo a Taxionomia Toponímica proposta por Dick (1990:.31-34), os antropotopônimos são

topônimos relativos aos nomes próprios individuais. Ex.: prenome: Abel (EH MG); Benedito (igarapé, MT); Fátima (EH MT); Maurilândia do Tocantins (TO); hipocorístico: Bentinho (EH MG); Chiquita (ilha MT); Nico (Igarapé, AC); prenome + alcunha: FernãoVelho (EH AL); Joaquim Preto (igarapé di, PA); Prenome + nome de família: Antônio Amaral (EH MG); Francisco Dantas (EH RN; Manuel Alves (rio GO)"(DICK, 1990: 32).

Os axiotopônimos, por sua vez, são "topônimos relativos aos títulos e dignidades de que se fazem acompanhar os nomes próprios individuais. Ex.: Presidente Prudente (EH SP); Doutor Pedrinho (EH SC); Duque de Caxias (EH RJ)" (DICK, 1990: 32) e os hierotopônimos são classificados como

topônimos relativos aos nomes sagrados de diferentes crenças: cristã, hebraica, maomentana, etc. Ex.: Bom Jesus do Tocantins (EH TO); Cristo Rei (EH PR); Jesus (rio GO); Alá (lago AM); Nossa senhora da Glória (EH AM); às efemeridades religiosas: Natividade (EH GO); Natal (EH AC); às associações religiosas: Cruz de malta (EH SC); aos locais de culto: igreja: serra da Igreja (PR); Capela: Capela (EH AL); Capelazinha (EH MG) (DICK, 1990: 33). 
Segundo o IBGE (2018), o município tem ao todo 46 unidades escolares, contudo, ao longo da pesquisa ora apresentada foi feita a análise de 16 nomes de escolas, sendo 12 antropotopônimos, 3 axiotopônimos (2 títulos de professor e 1 de marechal) e 1 hierotopônimo. A pesquisa cobriu apenas as escolas na região central de Marechal Cândido Rondon e, pelo objetivo deste estudo, apenas escolas com nomes próprios de pessoas. O registro dos dados foi feito mediante o preenchimento dos campos requisitados em fichas lexicográfico-toponímicas (exemplo abaixo) elaboradas pela Profa. Dra. Márcia Sipavicius Seide e pelo autor deste artigo em prol de integrar a informação disponível sobre cada escola. As informações aqui relatadas foram encontradas no $\mathrm{PPP}^{1}$ de cada instituição e em entrevistas com professoras que lecionaram nestas escolas.

Quadro - Ficha Lexicográfico-toponímica

\begin{tabular}{|c|c|}
\hline Pesquisador & Autor \\
\hline Data de registro dos dados & 11 de maio de 2020 \\
\hline Município & Marechal Cândido Rondon \\
\hline Localização & Rua 31 de março, 5300 - Jardim Ana Paula \\
\hline Topônimo & Escola Municipal Ana Paula \\
\hline Topônimo reduzido & Não se aplica \\
\hline Topônimo espontâneo & Não se aplica \\
\hline Topônimo anterior & Não se aplica \\
\hline Taxionomia & Antropotopônimo \\
\hline $\begin{array}{l}\text { Dados históricos do } \\
\text { homenageado }\end{array}$ & $\begin{array}{l}\text { A escola herdou o nome do bairro no qual se encontra. O Jardim Ana Paula teve } \\
\text { início em 02/07/1978 e recebeu o devido nome em homenagem à sobrinha de um } \\
\text { dos proprietários da imobiliária que projetou o bairro. }\end{array}$ \\
\hline $\begin{array}{l}\text { Importância do } \\
\text { homenageado }\end{array}$ & (X) Local ( ) Microrregional ( ) Regional ( ) Nacional ( ) Internacional \\
\hline Referências Bibliográficas & $\begin{array}{l}\text { Projeto Político Pedagógico da Escola Municipal Ana Paula } 2018 \text { (Documento } \\
\text { disponível na unidade escolar). }\end{array}$ \\
\hline Observação & \\
\hline
\end{tabular}

Fonte: elaboração do autor.

${ }^{1} \mathrm{O}$ Projeto Político Pedagógico é um documento que deve ser feito por todas as instituições escolares segundo a Lei de Diretrizes e Bases da Educação Nacional (LDB) de 1996. O documento contém informações sobre a instituição e a comunidade que atende, proposta pedagógica (metodologia de ensino) e diretrizes de funcionamento. 
Onomástica Desde América Latina, n.3, v.2, janeiro - junho, 2021, p. 154 - 176 ISSN 2675-2719 https://doi.org/10.48075/odal.v0i0.25692

A descrição dos dados que formam o corpora da pesquisa mostrado abaixo correspondem a uma organização em duas seções: escolas públicas e escolas particulares. As escolas públicas, devido à quantidade e diversidade de nomes, separam-se em cinco subseções, sendo elas: homenagem ao saber pedagógico, homenagem à literatura brasileira, homenagem aos pioneiros, homenagem a figuras políticas e populares e outros. Após a apresentação dos dados, seguir-se-á uma análise das circunstâncias da nomeação envolvendo as denominações e uma comparação ilustrada por meio de gráficos categorizando a natureza dos nomes apresentados.

\section{ESCOLAS PÚBLICAS}

\subsection{Homenagem ao saber pedagógico}

A Escola Municipal Jean Piaget está localizada na rua Minas Gerais, nº 188, no Centro. Esse antropotopônimo homenageia Jean William Fritz Piaget (1896-1980), biólogo, psicólogo e epistemólogo suíço, considerado um dos mais importantes pensadores do século XX. Defendeu uma abordagem interdisciplinar para a investigação epistemológica e fundou a Epistemologia Genética, teoria do conhecimento com base no estudo da gênese psicológica do pensamento humano (COLINVAUX, 2010: 6-19). Segundo o PPP (2019) da instituição, o nome da escola foi escolhido em reunião com professores. Anteriormente, a escola se chamava Grupo Escolar Marechal Rondon.

O Colégio Estadual Paulo Freire, localizado na rua Sete de setembro, nº 2441, no bairro Jardim Alvorada, configura-se como um antropotopônimo. O nome da escola homenageia Paulo Freire (1921-1997), Patrono da Educação Brasileira. Foi um educador e filósofo, tendo muita relevância na área da pedagogia como referência internacional. A escola revela certo grau de 
Onomástica Desde América Latina, n.3, v.2, janeiro - junho, 2021, p. 154 - 176 ISSN 2675-2719

influência da pessoa homenageada dentro de suas diretrizes institucionais ao mencionar em seu PPP que:

Dentro dos princípios de Paulo Freire que norteiam nossa escola, educador é aquele que educa, ensina sem olhar a quem, ele ensina sentindo, vendo o outro, compreendendo esse outro, mas não deve se importar com as diferenças, não deve querer padronizar todos, os educandos são diferentes e vão permanecer diferentes, iguais apenas no consentimento do direito e deveres (PPP do Colégio Estadual Paulo Freire, 2017: 59).

\subsection{Homenagem à Literatura Brasileira}

O nome da Escola Municipal Érico Veríssimo, localizada na rua Vitória, n⿳ 770 , no bairro Jardim Alvorada, também é um antropotopônimo: ele homenageia o escritor Érico Lopes Veríssimo (1905-1975), nascido em Cruz Alta, Rio Grande do Sul. Esse escritor recebeu o Prêmio Machado de Assis em 1953 por sua obra "Música ao longe" (1936), contudo, sua maior obra foi "O tempo e o vento"2. Foi convidado pelo governo americano a lecionar Literatura Brasileira na Universidade de Berkeley entre 1943 e 1945 e foi diretor de intercâmbio cultural da União Pan-Americana por três anos em meados dos anos 1950 (SMITH, 2013: 164-170). O Colégio Estadual Monteiro Lobato, localizado na rua Das Canelas, nº 295, no bairro Primavera, configura-se como um antropotopônimo. A escola iniciou suas atividades em 1987. O nome da escola homenageia Monteiro Lobato.

Lobato nasceu numa família de fazendeiros da cidade de Taubaté, São Paulo. Dedicouse a diferentes carreiras, negócios e campanhas. Quando estudante já demonstrava seu talento como escritor. Em suas obras buscou sempre valorizar um mundo caipira brasileiro, mesmo quando a literatura vivia com os olhos voltados para a Europa (PPP do Colégio Estadual Monteiro Lobato, 2019: 17).

O PPP (2019: 17) da escola esclarece como se deu a escolha do nome de Monteiro Lobato "por ele ter sido um defensor insubordinável dos interesses nacionais.” No PPP da escola 
encontra-se ainda a informação de que o "Sítio do Pica-pau amarelo" é tido como um exemplo para o seu ambiente educacional:

\begin{abstract}
Uma escola que garanta a articulação saudável entre o antigo e o novo, entre os valores do passado, a história, as convenções e a cultura, questionados sem que sejam destruídos, à semelhança da convivência das crianças do "Sítio do Pica-pau-amarelo" com Dona Benta, Visconde, Tia Nastácia, entre outros (PPP, 2019: 17).
\end{abstract}

\title{
1.3 Homenagem aos pioneiros
}

A Escola Municipal Antônio Rockenbach, localizada na rua Belém, no 887, no bairro Botafogo, configura-se como um antropotopônimo visto que o nome da escola homenageia Antônio Rockenbach. Segundo a própria diretora da escola, Franciele Storch, Antônio Rockenbach foi um dos três pioneiros na região e a escola foi uma das primeiras a serem construídas.

O Colégio Estadual Antônio Maximiliano Ceretta, localizado na rua Pres. Costa e Silva, n 1350 , no Centro, também se configura como um antropotopônimo, pois o nome da escola homenageia Antônio Maximiliano Ceretta, professor, vereador e radialista que, segundo informações do PPP da escola, se dedicava "a campanhas comunitárias em favor de menores carentes" (2017: 6). Após se mudar de sua cidade natal, Cachoeira, localizada no Rio Grande do Sul, ele muito contribuiu com o desenvolvimento do município de Marechal Cândido Rondon, sendo o primeiro diretor de comunicação da Rádio Difusora do Paraná em 1966 (2017: 6).

O antropotopônimo Colégio Estadual Frentino Sackser nomeia uma escola localizada na Avenida Maripá, no 3948 no bairro Higienópolis. Segundo as informações do PPP, o nome da escola homenageia Frentino Sackser, nascido em Passo Fundo, Rio Grande do Sul e que veio com sua família para Marechal Cândido Rondon em 1951. Ele se destacou nas organizações comunitárias em que participava, como, por exemplo, na diretoria da Comunidade Católica e da 
Escola Municipal Presidente Dutra do Botafogo, como sócio fundador do clube de futebol local, Esporte Clube Botafogo, dentre outras participações ativas. Sua formação escolar se limitava ao ensino primário, contudo, ele é citado no PPP da escola como "cidadão dotado de admirável capacidade intelectual" (2017: 7), era incentivador das atividades desportivas, sendo muito dedicado para com a comunidade.

A Escola Municipal Professor Osvino Carlos Weirich, localizada na rua Das Hortências, $\mathrm{n}^{\circ}$ 411, no bairro Jardim Higienópolis, configura-se como um axiotopônimo por conter, antes do nome próprio, um título. Segundo o PPP (2019), o nome da escola homenageia Osvino Carlos Weirich, um dos pioneiros e, também, um dos primeiros professores a atuar no município.

A Escola Municipal Waldomiro Liessem, localizada na avenida Rio Grande do Sul, $\mathrm{n}^{\circ}$ 3132, no bairro Jardim Marechal, apresenta-se como um antropotopônimo. O PPP (2019) informa que o nome da escola homenageia Waldomiro Liessem (1921-1972), nascido em Taquari, Rio Grande do Sul. Iniciou as atividades de professor em 1940 lecionando no Rio Grande do Sul e Santa Catarina. Veio para General Rondon³ em 1955, foi membro ativo na luta por melhorias para a educação rondonense tendo sido atendido pelo Governador do Estado do Paraná em 1956. Ainda segundo o PPP da escola, foi diretor do Colégio Evangélico Martin Luther de 1967 a 1972. Anteriormente, a escola se chamava Escola Municipal Professor Waldomiro

Liessem.

\subsection{Homenagem a figuras políticas e populares}

Outro antropotopônimo é o nome Colégio Estadual Eron Domingues, localizado na rua Mém de Sá, no 1615, no Centro. O nome da escola homenageia Heron de Lima Domingues

${ }^{3}$ General Rondon era um distrito administrativo de Toledo, criado em 1953 e emancipado a Município Marechal Cândido Rondon em 1960 (IBGE). 
(1924-1974), nascido em São Gabriel, no Rio Grande do Sul. Heron foi um jornalista e radialista brasileiro que atuou como apresentador de televisão, popularizou-se por noticiar acontecimentos históricos ao longo de seus 33 anos de carreira. Foi para o Rio de Janeiro em 1944 onde trabalhou no programa Repórter Esso, da Rádio Nacional, até 1962. De 1962 a 1974 foi apresentador de televisão na TV Tupi e posteriormente na Rede Globo. A escolha do nome se deu, segundo o PPP da escola (2019: 10), por meio de uma votação feita pela comunidade em 1971, envolvendo outros nomes no qual "Eron Domingues" foi o vencedor. Anteriormente, a escola se chamava Ginásio Estadual Marechal Cândido Rondon.

O Colégio Estadual Marechal Rondon, localizado na rua Tocantins, nº 2125 no bairro São Lucas, por sua vez, configura-se como um axiotopônimo, visto que homenageia o marechal Cândido Mariano da Silva Rondon ${ }^{4}$ (1866-1958), conhecido como Marechal Rondon, engenheiro militar e sertanista brasileiro, célebre por sua exploração do Mato Grosso e da Bacia Amazônica Ocidental e pelo suporte à comunidade indígena (IHGB).

A Escola Municipal Professor Bento Munhoz da Rocha Neto, por sua vez, está localizada na rua Dom João VI, $n^{\circ} 1370$ no Centro e seu nome configura-se como um axiotopônimo. O nome da escola homenageia Bento Munhoz da Rocha Neto (1905-1978), engenheiro, professor, escritor, sociólogo e político que foi deputado de 1946 a 1950, quando foi eleito Governador do Estado do Paraná. Em 1955, ele renunciou ao cargo e assumiu o Ministério da Agricultura. Entre 1958 e 1962 foi deputado federal.

\subsection{Outros}

A Escola Municipal Ana Paula, localizada na rua 31 de março, $\mathrm{n}^{\circ}$ 5300, no Jardim Ana Paula, é um antropotopônimo que a escola herdou a partir do nome do bairro no qual se encontra. 
Onomástica Desde América Latina, n.3, v.2, janeiro - junho, 2021, p. 154 - 176 ISSN 2675-2719

Conforme citado no PPP (2018) da escola, o Jardim Ana Paula teve início no dia 02 de julho de 1978 e recebeu este nome em homenagem à sobrinha de um dos proprietários da imobiliária que projetou o bairro.

\section{ESCOLAS PARTICULARES}

O nome do Colégio Cristo Rei enquadra-se como um hierotopônimo e localiza-se na rua Colombo, $\mathrm{n}^{\circ} 1128$ no Centro. Este topônimo é o único em sua categoria quando comparamos às outras escolas de Marechal Cândido Rondon. O nome da escola refere-se a Jesus Cristo, ou Jesus de Nazaré (7-2 a.C. - 30-33 d.C.), figura central do cristianismo. Em seu site, a escola declara que "o Colégio Cristo Rei é uma instituição de ensino confessionalmente cristã", evidenciando a influência do homenageado em suas diretrizes.

O Colégio Evangélico Martin Luther, assim como o Colégio Cristo Rei e diferentemente das escolas públicas já mencionadas, é uma escola religiosa e filantrópica localizada na Avenida Maripá, $n^{\circ}$ 865, no Centro. Configura-se como um antropotopônimo que homenageia Martin Luther (1483-1546), monge agostiniano e professor de teologia que pavimentou a Reforma Protestante, levantando-se veementemente contra diversos dogmas do catolicismo romano, criticando, principalmente, o comércio de indulgências (SILVA, 2020).

A escolha do nome remete ao contexto da criação da escola que se iniciou como Jardim de Infância, fundado pela OASE (Ordem Auxiliadora das Senhoras Evangélicas) em 1954. O grupo corresponde a um setor da Igreja Evangélica de Confissão Luterana no Brasil ${ }^{5}$, que exerceu fundamental influência na denominação da escola, visto que o vínculo da escola com a Comunidade Evangélica de Confissão Luterana culminou na eleição do nome Martin Luther, 
Onomástica Desde América Latina, n.3, v.2, janeiro - junho, 2021, p. 154 - 176 ISSN 2675-2719

como explica a Professora Liane Schwingel em relato oral: "A comunidade, por sua vez, tem esse nome, sim, pelo processo todo vinculado a Martin Lutero, né? Esse registro histórico de toda a importância de Martin Lutero no processo religioso e educacional”.

O Colégio Luterano Rui Barbosa, localizado na rua Dom Pedro I, n 1151, no Centro, configura-se como um antropotopônimo. O brasileiro Ruy Barbosa de Oliveira (1849-1923) foi um polímata ${ }^{6}$, jurista, advogado, político, diplomata, escritor, filólogo, jornalista, tradutor e orador. Coautor da constituição da Primeira República, atuou na defesa do federalismo, do abolicionismo e na promoção dos direitos e garantias individuais (FRAZÃO, 2019). Segundo o relato de Patrícia Helena Frai, professora do colégio: “A escolha desse nome está associada aos objetivos que a instituição pretendia: um ensino secular mais avançado, completo, diferente de outras escolas. Ruy Barbosa de Oliveira foi um grande intelectual do país, com pensamento a frente de seu tempo, por isso esse nome foi escolhido para o colégio." Anteriormente, a escola se chamava Ginásio Evangélico Ruy Barbosa.

\section{Análise}

Dentre os 16 nomes de escolas apresentados no decorrer deste artigo, apenas 1 topônimo feminino foi encontrado (Escola Municipal Ana Paula). Este resultado vai ao encontro das constatações do estudo de Seide e Silva (2020), cuja pesquisa envolvendo 57 nomes de ruas de Marechal Cândido Rondon que contém nomes próprios encontrou apenas quatro nomes próprios femininos. A partir de investigações por meio de documentos e entrevistas a pesquisa demonstrou que as quatro mulheres homenageadas o foram por algum tipo de vínculo (matrimonial ou parentesco) com algum homem de notoriedade, visto que informações relacionadas às mulheres eram mais difíceis de se encontrar do que a dos homens relacionados a elas. A denominação do bairro que se tornou também o nome da Escola Municipal Ana Paula ${ }^{6}$ Indivíduo que estuda ou que conhece muitas ciências. 
segue o mesmo padrão das mulheres homenageadas com nomes de ruas: a homenageada era sobrinha de um sócio da imobiliária que construiu o bairro. A discrepância na designação de nomes próprios masculinos e femininos em ruas de Marechal Cândido Rondon evidencia a desigualdade de gênero no âmbito toponímico ao assimilarmos esta tendência nos nomes de escola. Cabe também destacarmos um fato mencionado no PPP (2019: 10) do Colégio Estadual Eron Domingues em que, dentre os nomes disponíveis na votação que elegeu o atual nome da escola, havia os nomes de Cecília Meireles e Clarice Lispector (ambas escritoras), contudo, o radialista Heron Domingues teve seu nome escolhido.

Observando os gráficos abaixo percebe-se que a maior parte das homenagens por meio de nomes de escola remetem à história local ao prestigiar os pioneiros da região, correspondendo a 5 dos 16 nomes examinados.

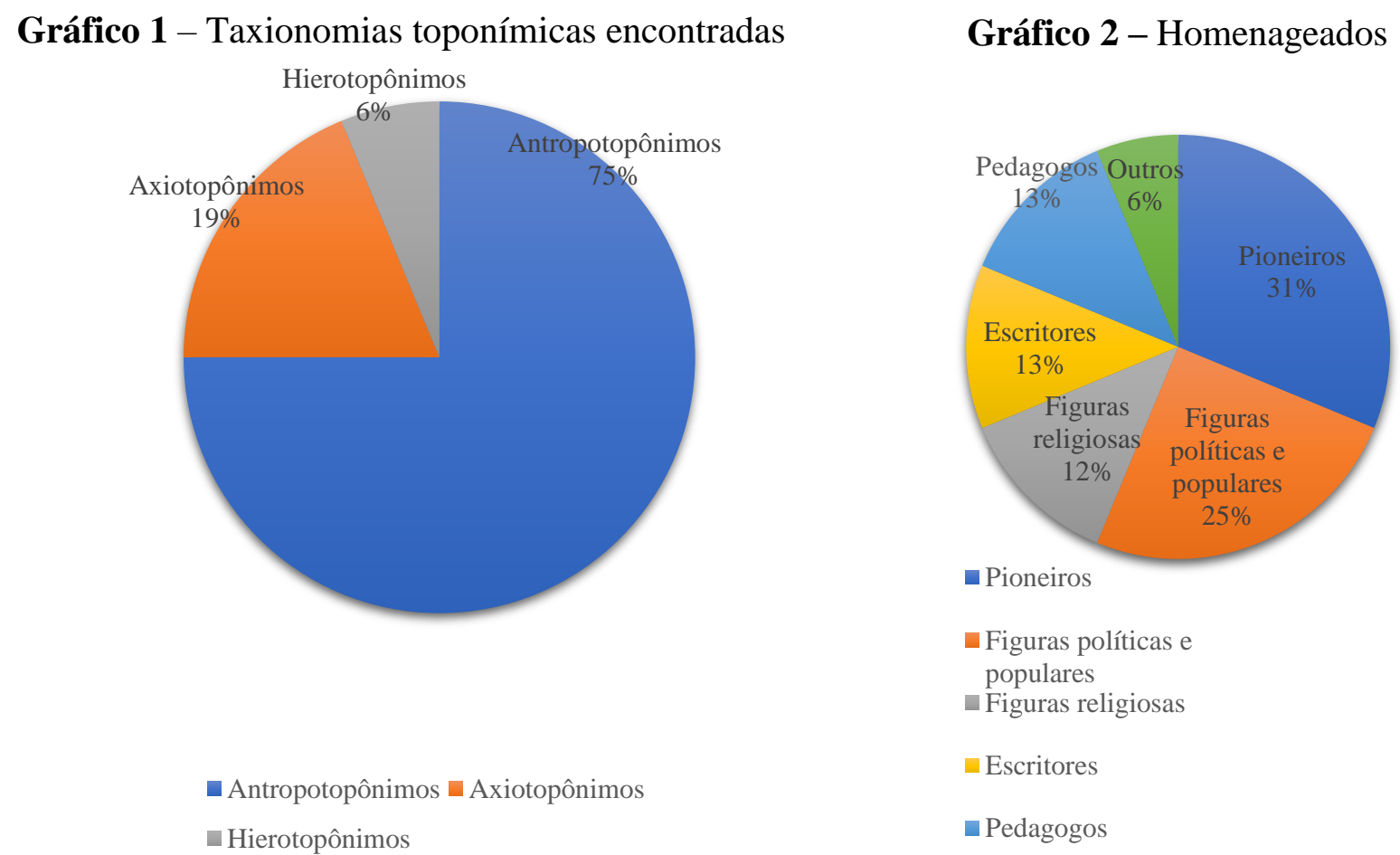

Fonte: elaboração do autor. 
Onomástica Desde América Latina, n.3, v.2, janeiro - junho, 2021, p. 154 - 176 ISSN 2675-2719

Notamos que a homenagem aos pioneiros concentra boa parte das nomeaações, visto que "no nome de um lugar subjaz a memória do lugar, o movimento da história, a história sociocultural da comunidade" (BASTIANI, 2016: 56), como vimos anteriormente, a preservação da história se dá, em parte, por meio das memórias atribuídas a topônimos.

\footnotetext{
No que se refere especificamente aos nomes das escolas, é válido mencionar que os sentimentos de identidade e pertencimento podem ser reforçados a partir do entendimento de que no nome da escola pode estar subjacente um pouco da memória do lugar e um pouco da história sociocultural da comunidade (BASTIANI, 2016: 132).
}

A presença de nomes de políticos e pessoas de notoriedade em topônimos é explicada quando observamos a territorialização que um nome proporciona a um lugar. Para Bastiani, o nome é "um veículo de afirmação de poder" (2016: 61). Segundo Tonucci Filho, o território pode ser demarcado como "cultural ou simbólico-cultural, em que o território é entendido como produto da apropriação/valorização simbólica e subjetiva de um grupo em relação ao seu espaço vivido" (2013: 46). Em relação a essa apropriação subjetiva, Bastiani diz que "pode ser melhor compreendida quando o nome dado a uma instituição escolar se trata de um nome próprio de pessoa" (2016: 63).

Por meio dos estudos toponímicos exercidos nesta pesquisa, podemos esclarecer que na maioria dos nomes de escola aqui analisados encontramos fortes referências à história local, contudo, não só nas homenagens aos pioneiros do município, mas também em homenagens de demais pessoas que permitiram-nos encontrar memórias de tendências políticas, religiosas e sociais na cidade de Marechal Cândido Rondon.

\section{Considerações finais}

No decorrer do artigo exploramos quem são os indivíduos homenageados em nomes de escolas de Marechal Cândido Rondon. Discorreu-se também sobre a importância do nome 
próprio como criador de significados dentro de uma língua, e esta, por sua vez, como um dos elementos principais de um povo enquanto vestígio indispensável nos estudos toponímicos, revelando traços socioculturais e tendências históricas. Para tanto, observamos como a interdisciplinaridade é essencial à metodologia da Toponímia, uma vez que a abordagem de várias áreas de estudo nos traz toda a complexidade de informações necessárias para a realização das pesquisas sobre nomes de lugar.

A partir da pesquisa realizada, podemos verificar, por meio dos dados analisados, diversos fatos e pontos que, de outra forma, isto é, sem um estudo toponímico, jamais seriam explicitados. O levantamento de informações sobre as pessoas homenageadas revelou suas relações com a comunidade, política, religião e sociedade, portanto, pertinente à sociedade rondonense como também a desigualdade de gênero evidenciada nas homenagens em topônimos que, em conjunto com outros estudos toponímicos, acrescenta ainda mais valor a Toponímia frente à percepção e problematização de questões sociais nos mais diversos âmbitos.

Tendo em vista a valorização da história local de Marechal Cândido Rondon seria interessante o desenvolvimento de mais pesquisas toponímicas locais, visto que, conforme salientou-se no artigo, elas abordam mais do que nomes e lugares, elas envolvem toda a construção social do espaço nomeado.

\section{Referências}

Recebido em 26/08/2020

Aceito em 14/10/2020

Publicado em 17/12/2020

Andrade, Karylleila Santos (2017). O lugar nos estudos toponímicos: reflexões. Revista De Estudos Da Linguagem, [S.1.], v. 25, n. 2, p. 585-607, mar. Disponível em: <http://periodicos.letras.ufmg.br/index.php/relin/article/view/9547>. Acesso em: 20 set 2020. doi:http://dx.doi.org/10.17851/2237-2083.25.2.585-607. 
Bastiani, Carla (2016). Relações entre nome e lugar: estudo dos nomes das escolas públicas de Porto Nacional em uma perspectiva interdisciplinar da Geografia e da Toponímia. Dissertação (Mestrado Acadêmico) - Universidade Federal do Tocantins, Araguaína.

Bastiani, Carla; Andrade, Karylleila Santos; Pereira, Carolina Machado Rocha Busch (2018). Toponímia e geografia: diálogos possíveis no contexto da teoria da interdisciplinaridade. Caminhos da Geografia, v.19, n.65, UFU. Online, 109-124.

Brandão, Analídia dos Santos; Abbade, Celina Márcia de Souza (2016). Os antropotopônimos na Bahia de Todos os Santos: uma análise social e linguística. Revista GTLex, v. 1, n. 2, 312-325. https://doi.org/10.14393/Lex2-v1n2a2016-5

Cândido Mariano da Silva Rondon. Instituto Histórico e Geográfico Brasileiro, (2015). Disponível em: <https://ihgb.org.br/perfil/userprofile/cmdsrondon.html>. Acesso em: 13 de julho de 2020.

Colinvaux, Dominique (2010). História da Pedagogia: pensador rigoroso, homem afável. Revista Educação, São Paulo, n. 1, 6-19.

Dick, Maria Vicentina de Paula do Amaral (1990). A motivação toponímica e a realidade brasileira. São Paulo: Arquivo do Estado.

Dick, Maria Vicentina de Paula do Amaral (1992). Toponímia e Antroponímia no Brasil: Coletânea de estudos. São Paulo: Arquivo do Estado.

Faria, Glauciane Santos (2018). Tradição e memória: um estudo antroponímico dos nomes de logradouros da cidade de Ponte Nova - Minas Gerais / Tradition and memory: an anthroponymic study of the names of the city of Ponte Nova - Minas Gerais. Revista De Estudos Da Linguagem, [S.1.], v. 26, n. 3, p. 1151-1174, june. Disponível em: <http://www.periodicos.letras.ufmg.br/index.php/relin/article/view/12998>. Acessado em: 22 set 2020. doi:http://dx.doi.org/10.17851/2237-2083.26.3.1151-1174.

Frai, Patrícia Helena. (2020). Depoimento concedido ao autor. Marechal Cândido Rondon, 15 de junho de 2020.

Frazão, Dilva. Biografia de Rui Barbosa. Ebiografia, 2019. Disponível em: <https://www.ebiografia.com/rui_barbosa/>. Acesso em: 13 de julho de 2020.

Guiraud, P. (1989). A semântica. Rio de Janeiro: Betrand Brasil.

Instituto Brasileiro de Geografia e Estatística - IBGE. (Paraná). Censo Demográfico de 1960. Paraná. Disponível em: <http://bibilioteca.ibge.gov.br>. Acesso em: 20 mar. 2014.

. Censo (2010). Mapa interativo. Variável religião por município. (Rio de Janeiro, RJ). Disponível em: <http://www.censo.ibge.gov.br/apps/mapa>. Acesso em: 20 mar. 2014.

(2020). Histórico de Marechal Cândido Rondon. (Paraná). Disponível em: <https://biblioteca.ibge.gov.br/visualizacao/dtbs/parana/marechalcandidorondon.pdf $>$. Acesso em: 13 julho 2020.

(2018). IBGE Cidades - Marechal Cândido Rondon (Paraná). Disponível em: <https://cidades.ibge.gov.br/brasil/pr/marechal-candido-rondon/panorama>. Acesso em: 13 setembro 2020. 
López Franco, Yolanda G. (2020). Las relaciones intercategoriales e intracategoriales en antroponimia. El caso de los nombres de pila en francés de Francia y en español de México. Onomástica Desde América Latina, n.1, v.1, 2020, 214 -239. Disponível em < http://erevista.unioeste.br/index.php/onomastica/issue/view/1139> Acesso em 12 agosto 2020.

Ogden, Charles Kay; Richards, Ivor Armstrong ([1923]1972). O significado do significado: um estudo da influência da linguagem sobre o pensamento e sobre a ciência do simbolismo. Tradução de Álvaro Cabral. Rio de Janeiro: Zahar.

. ([1923]1989). The meaning of the meaning: a study of the influences upon thought and of the science of symbolism. Harvest: HBJ.

Oliveira, A. M. P. P. de; Isquerdo, A. N. (Org.) (1998). As ciências do léxico: lexicologia, lexicografia, terminologia. Campo Grande-MS: Ed. UFMS.

PROJETO POLÍTICO PEDAGÓGICO 2018. Escola Municipal Ana Paula (Documento disponível na unidade escolar).

PROJETO POLÍTICO PEDAGÓGICO 2018. Escola Municipal Professor Bento Munhoz da Rocha Neto (Documento disponível na unidade escolar).

PROJETO POLÍTICO PEDAGÓGICO 2017. Colégio Estadual Antônio Maximiliano Ceretta. Disponível em: <http://www.mrhantonioceretta.seed.pr.gov.br/modules/conteudo/conteudo.php?conteudo=17>. Acesso em: 29 de abril de 2020.

PROJETO POLÍTICO PEDAGÓGICO 2019. Escola Municipal Érico Veríssimo (Documento disponível na unidade escolar).

PROJETO POLÍTICO PEDAGÓGICO 2019. Colégio Estadual Eron Domingues. Disponível em:

<http://www.mrherondomingues.seed.pr.gov.br/redeescola/escolas/27/1470/14/arquivos/File/PP P/PPP2019.pdf>. Acesso em: 29 de abril de 2020.

PROJETO POLÍTICO PEDAGÓGICO 2017. Colégio Estadual Frentino Sackser. Disponível em: <https://drive.google.com/file/d/0B5DKXqWKU1p5MDZaMmUxQjBOZTg/view>. Acesso em: 29 de abril de 2020.

PROJETO POLÍTICO PEDAGÓGICO 2019. Escola Municipal Jean Piaget (Documento disponível na unidade escolar).

PROJETO POLÍTICO PEDAGÓGICO 2019. Colégio Estadual Monteiro Lobato. Disponível em: <https://drive.google.com/file/d/169KQfPB4NmZO9rWo2i73LUT8o-K1EXUy/view>. Acesso em: 29 de abril de 2020.

PROJETO POLÍTICO PEDAGÓGICO 2019. Escola Municipal Professor Osvino Carlos Weirich (Documento disponível na unidade escolar).

PROJETO POLÍTICO PEDAGÓGICO 2017. Colégio Estadual Paulo Freire. Disponível em: $<$ https://drive.google.com/file/d/1s5PRejcFEGoER8hhnjfDDByWuvammSLZ/view>. Acesso em: 29 de abril de 2020. 
PROJETO POLÍTICO PEDAGÓGICO 2019. Escola Municipal Waldomiro Liessem (Documento disponível na unidade escolar).

Reyes Contreras, Miguel (2020). Sobre antroponimia en las calles de Santa Fe, Nuevo México Onomástica Desde América Latina, n.2, v.1, p. 122-143. Disponível em <http://erevista.unioeste.br/index.php/onomastica> Acesso em 12 agosto 2020.

Sapir, E. (1961). Linguística como ciência: Ensaios. Rio de Janeiro: Livraria Acadêmica.

Saussure, Ferdinand de. ([1916]2006). Curso de Linguística Geral. Tradução: Antônio Chelini, José Paulo Paes e Izidoro Blinkstein. 27 edição. São Paulo: Editora Cultrix, 79-80.

Schwingel, Liane. Depoimento concedido ao autor. Marechal Cândido Rondon, 25 de maio de 2020.

Schwingel, Liane. Colégio Evangélico Martin Luther: Memórias e Imagens. Monografia apresentada no curso de História da UNIOESTE - Universidade Estadual do Oeste do Paraná, como requisito parcial para a conclusão do curso - Campus de Marechal Cândido Rondon, 2003.

Seide, M. Sipavicius (2016). A identidade religiosa na antroponímia de Marechal Cândido Rondon. Revista De Estudos Da Linguagem, [s.1.], v. 24, n. 1, 167-186, fev. Disponível em: http://dx.doi.org/10.17851/2237-2083.24.1.167-186. Acesso em: 13 de julho de 2020.

Seide, Márcia Sipavicius, \& Silva, Bianca Nagai da (2020). Desigualdade de gênero na toponímia. Revista GTLex, v. 3, n. 1, 133-145, 22 fev. Disponível em: https://doi.org/10.14393/Lex5-v3n1a2017-8 Acesso em: 13 de julho de 2020.

Smith, Richard Cándida (2013). Érico Veríssimo, um embaixador cultural nos Estados Unidos. Tempo, v. 19, n. 34, 147-173, jan. /jun. Disponível em: https://doi.org/10.5533/TEM1980-542X-2013173412. Acesso em: 12 de julho de 2020.

Silva, Daniel Neves. "Martinho Lutero"; Brasil Escola. Disponível em: <https://brasilescola.uol.com.br/historiag/martinho-lutero.htm> Acesso em: 26 de julho de 2020.

Site do Colégio Cristo Rei. Disponível em: <http://www.cristoreimcr.com.br/instituicao/10/quem-somos> Acesso em: 13 de julho de 2020.

Storch, Franciele. Depoimento concedido ao autor. Marechal Cândido Rondon, 11 de maio de 2020 .

Tavares, Marilze (2009). Língua e cultura: considerações sobre a motivação de nomes geográficos indígenas. Raido, Dourados, v. 3, n. 6, 95-109, jul. /dez. Disponível em: http://ojs.ufgd.edu.br/index.php/Raido/article/view/434. Acesso em: 28 de junho de 2020.

Tonucci Filho, João Bosco Moura. Espaço e território: um debate em torno de conceitos-chave para a Geografia Crítica. Revista Espinhaço, [s.l.], v.2, n. 1, 41-51, junho/2013. Disponível em: http://www.revistaespinhaco.com/index.php/journal/article/view/16.

Acesso em: 29 de julho de 2020.

Ullmann, Stephen ([1962]1964). Semântica: uma introdução à ciência do significado. Tradução J. A. Osório Mateus. Lisboa: Fundação Calouste Gulbenkian. 